\title{
Research on Static Var Compensation Control Technology for Wind Power Grid
}

\author{
Fucheng Lang \\ Electric Power Research Institute of State Grid Liaoning Electric Power Co., Ltd., Shenyang 110006, China. \\ High Voltage and Large Current Laboratory of State Grid Corporation, Shenyang 110006, China
}

Hongkui Zhang

CCTEG Shenyang Research Institute, Fushun 1131226, China

\begin{abstract}
In order to reduce the influence of wind power integrated into grid in power system, carried out simulation analysis on static Var compensator control the impact of wind power integrated into grid process. On the basis of research on squirrel cage induction wind turbines and Static Var Compensator (SVC), system model containing the squirrel cage wind farm was built using the PSCAD software, and reactive power and voltage of export simulation in the case of system instantaneous three-phase short-circuit fault was achieved with the presence or absence of the SVC in wind farms and outlets. Comparative analysis of simulation results shows that the reactive power compensation device in the wind power system greatly improved the system's ability to recover (transient faults) and inhibition of voltage drop.
\end{abstract}

KEYWORD: Wind Power Farm; SVC; Control; Var Compensator; PSCAD.

\section{INTRODUCTION}

With the increase of national energy demand and the limit of conventional energy reserves, the development of wind energy, solar energy, biomass and other new energy sources is the trend of China's energy industry. Wind energy is a new kind of energy which has abundant reserves, wide distribution and environmental protection, with the advantages of abundant reserves, wide distribution and environmental protection. So the wind energy is a new type of energy, which has great development potential and good prospects for commercial development. China's rapid development of wind power technology, the new wind power in 2014 reached a record high, according to preliminary statistics: 2014 wind power installed capacity of 23350500 kilowatts, an increase of 114763390 , the total installed capacity of wind power up to $45.1 \%$ kilowatts, an increase of $25.5 \%$.

Due to the obvious control of wind power, the power system voltage stability can be influenced by the wind power generator and the power system can be built up. Static (var compensator SVC) is a power electronic technology to realize the power supply and adjustment. It can provide reactive power support to the rapid recovery of the voltage of the power system. Therefore, it is very important to carry on the research on the reactive power compensation strategy for the power system in the wind turbine power system.

\section{WIND ELECTRIC FIELD}

\subsection{Components of Wind Power Generation System}

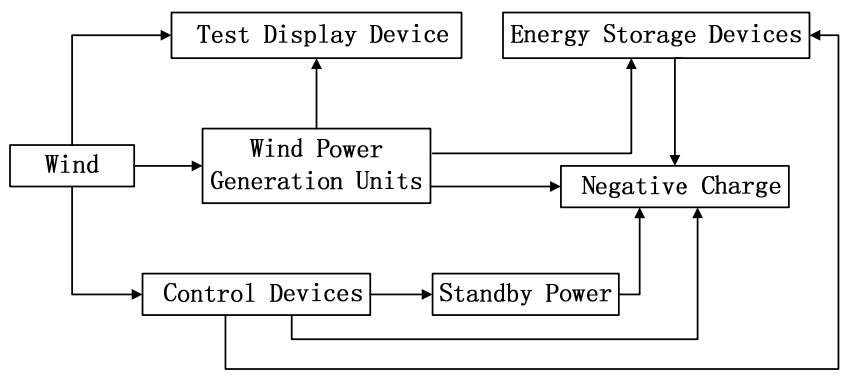

Fig. 1 Structure of wind power generation system

Wind power generation system is a combination of the various functional units, which will be collected from the wind power and transport to the power grid. The structure is complex, mainly consisting of wind, wind power generation units, control devices, energy storage devices, standby power, test display device and negative charge, etc. [3-4]. Wind energy is the source of energy for the system, and the wind power generation units will be converted into electrical energy, and the control device can realize the effective control and regulation of the power generation process. The detection device is used to monitor 
and display the system state, and the structure of the wind power electric field is shown in Fig. 1.

\subsection{Wind Farm Connected to Power System}

Asynchronous generator system are applied mostly in wind farm power generation equipment, which transmits active power, but also absorbing reactive power from the grid, at the same time, box transformer, power transformer, set electric lines, wind power transmission line are also consumed by a large number of reactive power, resulting in the decrease of wind power grid power factor. In addition, due to the control ability of the wind power, the wind speed fluctuations will cause the wind energy output to change, affecting the quality of the power grid [5]. Taking the asynchronous wind power generation system as an example, the problem of wind power integration is analyzed from the aspects of power quality, system voltage stability and grid impact.

Effect of wind power variations are mainly affected by the change of wind speed, turbulence, asynchronous generator wake effect and tower shadowing effect. Voltage flicker, voltage fluctuation, voltage sag and periodic voltage fluctuation are the main forms of the influence of wind power fluctuation on the voltage of wind farm. At the same time, voltage fluctuations in the range of a certain range, it will also be sensitive to the normal operation of the power system caused a certain impact.

Traditional transmission and distribution network power transmission direction connects as one way, which is the power transmission system from the transmission system into the distribution network and then down the load, and the wind power access to power grid changes in the distribution network power flow characteristics, so that the flow distribution and flow changes. When the wind power is injected into the traditional power grid, the power of the wind power is increasing. The local grid voltage in the wind farm is in the safe range of the original design, causing the voltage collapse [6]. In addition, in the power system voltage level is low, the wind farm reactive power compensation of the shunt capacitor is rapidly reduced, so that the wind farm reactive power demand to further rise, causing the deterioration of voltage level, when the deterioration is serious it will also cause voltage collapse.

Asynchronous wind power generator itself has no excitation device, and the process of grid connection needs to pass the transition process of 5-6 times of the rated current, which usually lasts a few hundred milliseconds. Wind turbine is incorporated into the small volume of the power grid, the closing moments will lead to voltage fell significantly, the effect with a grid of other equipment normal operation, and the stability and security of the whole power system have great influence.

\section{MATHEMATICAL MODEL}

\subsection{Mathematical Model of Wind Turbine}

Wind turbines absorb the wind energy cannot be converted into the mechanical energy of the wind turbine generator, and the conversion efficiency of wind energy can be deduced from the German scientist Baez's Betz theory [7]. The maximum efficiency of the wind energy conversion to mechanical energy is the ideal wind turbine, which is the ideal wind energy utilization coefficient:

$$
\eta_{\text {max }}=\frac{16}{27} \approx 0.593
$$

Wind turbine and squirrel cage induction generator wind electric power generation unit, wind machinery can conversion efficiency was influenced by the type of wind turbine and generator, reality of wind energy utilization coefficient is less than ideal wind energy utilization coefficient and actual wind farm output power characteristic equation:

$P_{\text {mech }}=\frac{1}{2} \rho \pi R^{2} v^{3} C_{\mathrm{p}}$

The $\rho$ is air density, usually select $1.25 \mathrm{~kg} / \mathrm{m} 3, \mathrm{R}$ stands for wind turbine wind wheel radius, stands for wind equivalent wind speed, $\mathrm{Cp}$ is actual wind farm wind energy utilization coefficient and horizontal axis wind turbine in $\mathrm{Cp}=0.2 \sim 0.5$, the vertical axis wind turbine $\mathrm{Cp}=0.3 \sim 0.4$.

\subsection{Mathematical Model of Asynchronous Generator}

Through the reasonable control of the asynchronous machine, the rotor speed and the direction of the rotor can be adjusted to make the induction machine run in three kinds of state. Work in power under the condition of stable operating region of the asynchronous motor electromagnetic torque and slip is proportional to that slip is faster, $T$ type equivalent circuit of asynchronous generator as shown in Fig. 2.

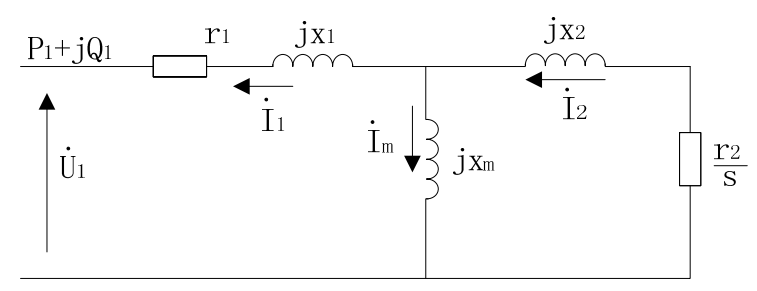

Fig. 2 Equivalent circuit of asynchronous generator T

In Fig. 2 P1 indicates induction generator active power, Q1 says for asynchronous generator reactive power, U1 says for asynchronous generator voltage, I1 says current for the induction generator, R1 says as the resistance of the asynchronous generator X1 represents for asynchronous generator leakage reactance, Im expresses as the magnetizing branch cur- 
rent, XM says as the magnetizing branch reactance, I 2 is converted to the stator side of the rotor current, Artoo is converted to the stator side of the rotor resistance, X2 represents the converted to the stator rotor leakage reactance; s slip. According to Fig. 2, the active power and reactive power of the asynchronous generator are respectively:

$P_{1}=\operatorname{Re}\left[\dot{U}_{1} \hat{I}_{1}\right]=\operatorname{Re}\left[\frac{U_{1}^{2}}{\hat{Z}}\right]$

Where

$$
Z=r_{1}+j x_{1}+\frac{\left(j x_{2}\right)\left(\frac{r_{2}}{s}+j x_{2}\right)}{\left(\frac{r_{2}}{s}\right)+j\left(x_{m}+x_{2}\right)} \text {. }
$$

\section{STATIC VAR COMPENSATION DEVICE}

Static var compensation device (SVC) is a new type of reactive power compensation technology developed rapidly in the 70 's in twentieth Century. The capacity of the capacitor and reactor of the power system is regulated by the control of the thyristor. According to the difference of control mode and object, SVC is divided into TSR and TCR (TCR), and TSR can be mixed with TSR+TCR, and can be combined into $\mathrm{TSR}+\mathrm{FC}, \quad \mathrm{TCR}+\mathrm{FC}$ or TSR+TCR+FC with fixed capacitor (FC). In the application of load compensation, the use of TCR+FC combination mode can be achieved in accordance with the requirements of compensation for the change of random real-time compensation, to ensure the stability of the power grid voltage, which is shown in Fig. 3.

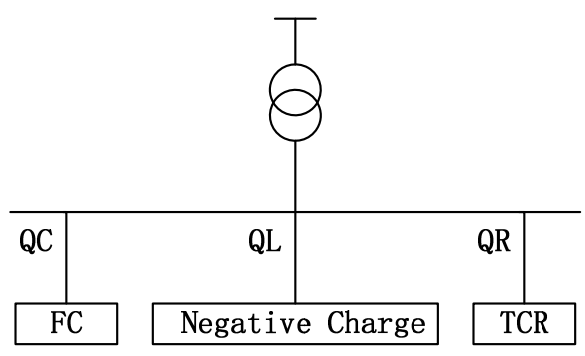

Fig. 3 FC+TCR type compensation device wiring diagram

\section{WIND ELECTRIC FIELD SIMULATION}

Because the squirrel cage induction generator has the dual characteristics of active power and reactive power, it can not provide reactive support to the power system, so the stability of the system may be seriously affected. According to the actual operating conditions of the wind farm power network, the model of the study object is set up as shown in Fig. 4. The variation of voltage and reactive power of the wind farm with the wind farm is studied under the condition of SVC. The power network model is composed of the wind farm, the bus, the booster sta- tion, the SVC and the power network. The wind farm is composed of 10 constant speed squirrel cage induction generator, the capacity of $1.5 \mathrm{MW}$, and the total installed capacity of $15 \mathrm{MW}$. The voltage of the wind farm inputs to the boost station is $0.398 \mathrm{kV}$, which is converted into $230 \mathrm{kV}$ after the boost to the transmission line to the power network.

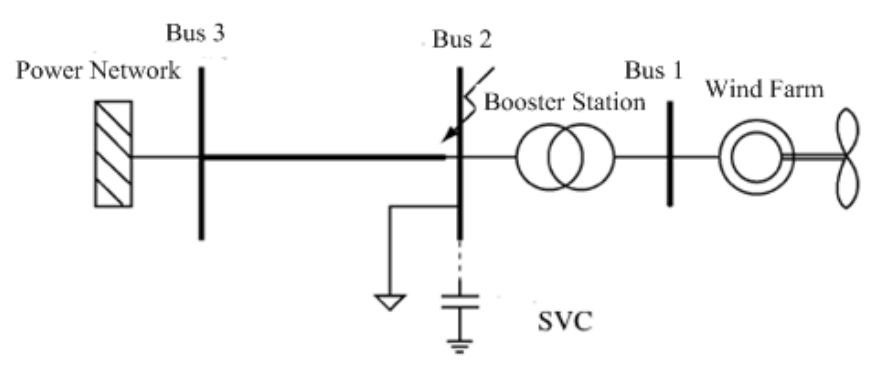

Fig. 4 Schematic model of power grid with wind farms

According to the wind farm power grid model established in Fig. 4, the simulation model of the system is built by using the wind farm grid connected characteristics simulation software PSCAD, as shown in Fig. 5. The condition of simulation analysis is that the whole wind power generation unit is connected to the power grid at 0 s time, and the network is 1 . The system has three-phase short-circuit faults after running $1 \mathrm{~s}$, and the power network is returned to normal after $0.05 \mathrm{~s}$.

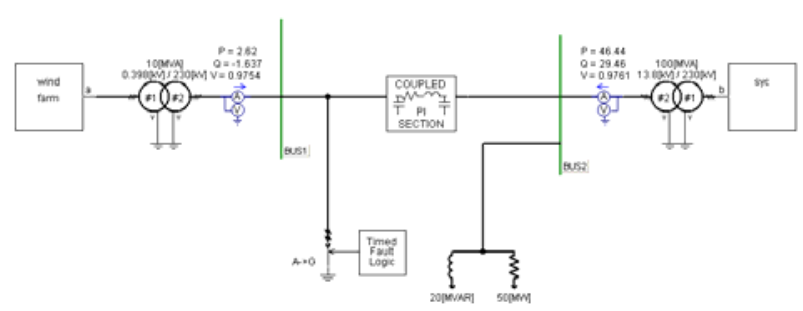

Fig. 5 Simulation model of power system with wind farm

\subsection{System Simulation without Adding SVC}

When reactive power compensation measures are not taken, when large-scale wind turbines connected to the grid, the wind farm will lead to the entrance of the voltage drop and sharp fluctuations in the value. After the failure of the power system voltage drop, resulting in asynchronous generators output dropped sharply, and the absorption of reactive power will decline rapidly. The network failure and voltage curve are shown in Fig. 6, as voltage fluctuation curve shows, including wind farm grid in case of system failure, voltage fluctuation is large, when the fault is ended, the network voltage can not be quickly restored to normal voltage level. When the power system without adding any reactive power compensation and network failure occurs, the reactive power 
curve is shown in Fig. 7, the figure shows that when wind farms absorb reactive power due to reduced active power output is reduced, and the failure fluctuates as well.

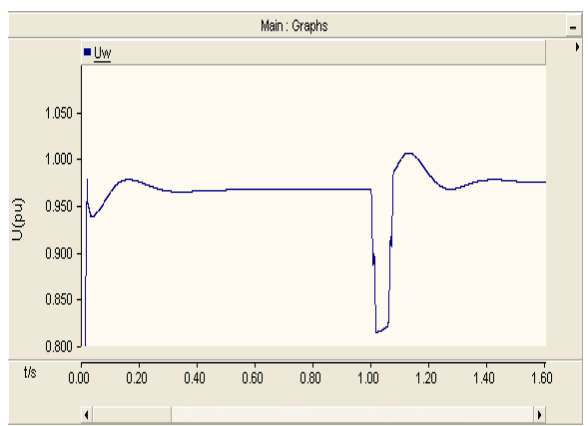

Fig.6 Outlets voltage curve of wind farms

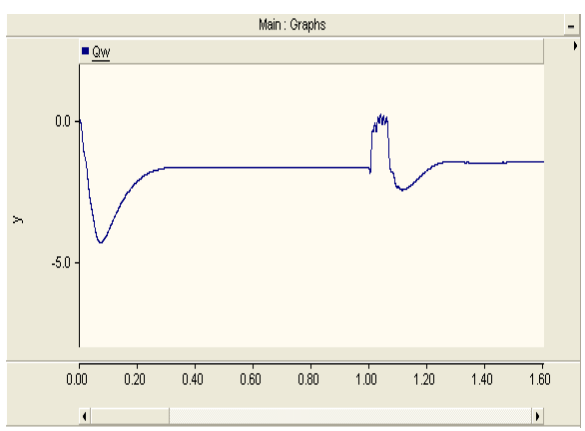

Fig.7. Outlets reactive power curve of wind farms

\subsection{System Simulation after Adding SVC}

For the network voltage and reactive power characteristics of wind power, rapid response installation inductive (inductive) or capacitive (capacitance) devices were applied to solve the problem for reactive power control. In this paper, installation of SVC were made at the bus two outlets for centralized reactive power compensation device, using PSCAD software running again, and outlets for voltage and fault voltage simulation curve as shown in Figure 8. Comparing with Figure 6, the fault outlet voltage before and after the wind farm was significantly closer to $1 \mathrm{p} . \mathrm{u}$, when failure occurs the decreases dropped significantly, and quickly returned to the grid after the fan pre-fault levels, the simulation curve is relatively smooth. After the installation of SVC and reactive power curve wind farms shown in Figure 9, comparing this simulation curve with Figure 7, fault before wind farms absorb reactive power change. During the failure, since the compensation effect of SVC wind farm voltage drop is not much, there is no significant reduction of the active power output, reactive power will not change much, ensuring the normal operation of the system.

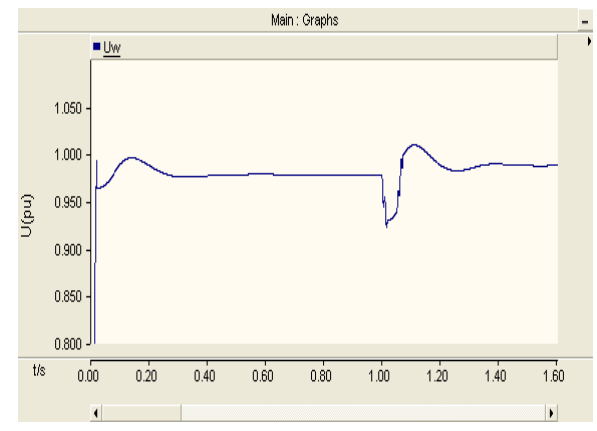

Fig. 8 Outlets voltage curve after the SVC installation of wind farms

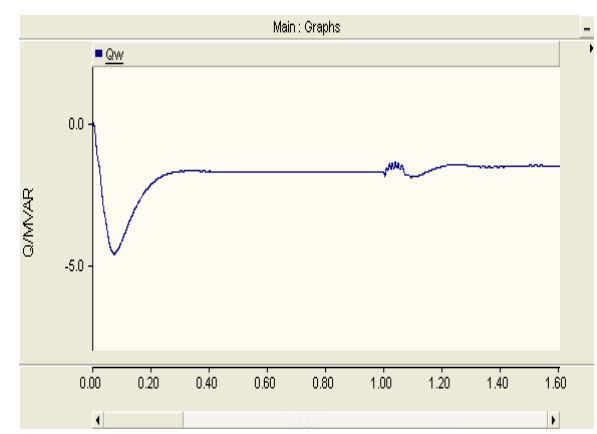

Fig. 9 Reactive power curve after the SVC installation of wind farms

Through simulation results comparison it shows that after adding reactive power compensation device SVC in wind farm grid, when the wind turbine grid and power grid failure occurs, the system can provide a portion of reactive power support, significantly improved voltage stability and power quality but also improve the LVRT squirrel cage induction wind turbines.

\section{CONCLUSIONS}

In this paper, the problem of reactive power squirrel cage and wind farms, and the impact on system voltage stability after the network were analyzed theoretically. Static var compensator (SVC) is applied to the wind power system, and by comparing simulation analysis it shows that when the system is a transient phase short-circuit fault, SVC achieves a good compensation effect, improving voltage stability at wind farms, significantly reducing the reactive power fluctuations of wind farms, which has a very good improvement on transient characteristics of the wind farm.

\section{REFERENCES}

Duque A J,Castronuovo E D,Sanchez I. Optimal Operation of a pumped-storage hydro plant that compensates the imbalances of a wind power producer[J].Electric Power Systems Research,2011, (81):1767-1777. 
Erlich I,Nakawiro W,Martinez M.Opti mal dispatch of reactive sources in wind farms[A].2011 IEEE Power and Energy Society General Meeting[C].Detroit:IEEE,2011.1-7.

He Guixiong,Chao Qin,Tian Yizhi,et al.Research on the dynamic equivalent parameter aggregation of fixed-speed wind turbines in wind farm[J].Renewable Energy Resources,2009,27(1):14-18.I.S. Jacobs and C.P. Bean, "Fine particles, thin films and exchange anisotropy," in Magnetism, vol. III, G.T. Rado and H. Suhl, Eds. New York: Academic, 1963, pp. 271-350.

Li Hui,Wang Hesheng,Shi Xuyang,et al.Study on equivalent model of wind farms based on genetic algorithm[J].Power System Protection and Control,2011,39(11):1-8.

Qin Tao,Lv Yuegang,Xu Daping.Reactive power control of wind farm adopting doubly-fed induction generators[J]. Power System Technology,2009,33(2):105-110.

Sumalili J,Keko H,Miranda V. Clustering-based wind power scenario reduction technique[A].Stockholm,Sweden:Curran Associates,2011.391-398.

Sumalili J,Keko H,Miranda V. Clustering-based wind power scenario reduction technique[A]. Huang Wei, Zhang Xiaozhen. Feature analysis based equivalent modeling for large-scale wind farms [J]. Power System Technology,2013, 37(8):2271-2277..

Zhang Jianping,Li Dongliang,Han Yi.Analysis of deflection and stress for large wind turbine blade under different average wind speeds[J]. Renewable Energy Resources, 2012, 30(7): 37-40. 